\title{
KNOWLEDGE MANAGEMENT AND ORGANIZATIONAL CULTURE: AN EXPLORATORY STUDY
}

\author{
Bing Li, Jianpeng Zhang, Xiaoxia Zhang
}

\begin{abstract}
Purpose of the article Knowledge has been considered as the strategic assets and become the source of competitive advantage in organizations. Knowledge management thus receives the extraordinary attention from the top management. Many organizational factors have influences on knowledge management practices. This paper attempts to explore the empirical relationship between knowledge management and organizational culture in the specific situation of China's commercial banking industry.

Methodology/methods The relationship between knowledge management and organizational culture is quantitatively investigated by surveying bank managers. The scale of SECI modes is used to measure knowledge management process and the scale of Denison Organizational Culture Survey (DOCS) is used to measure organizational culture. We explore the underlying relationship by employing the statistical analyses such as correlation, regression and structural equation modeling. Scientific aim The research aims at testing the relationship between knowledge management and organizational culture, and furthermore if there exist linkages between cultural traits and SECI modes. Findings The results of the empirical study confirm the great and positive effect that organizational culture has on knowledge management. Different cultural traits contribute to different SECI modes. Conclusions For obtaining successful knowledge management practices in organizations, it is better to concern about the relationship between knowledge management and organizational culture. The limitation in the paper is the sampling size, which will be solved by an industry-wide survey in our future research.
\end{abstract}

Keywords: knowledge management; organizational culture; DOCS; SECI

JEL Classification: D83, M14

\section{Introduction}

In this era of knowledge-based economy, knowledge management has been one of the most important strategic actions in organizations. Knowledge is at center stage of knowledge management practices and involves human participation (Davenport et al., 1998).

Drucker (1999) has stated that "The most valuable asset of a 21 st-century institution (whether business or nonbusiness) will be its knowledge workers and their productivity." Knowledge can be categorized into different types, such as tacit or explicit (Polanyi, 1983). The tacit or explicit knowledge is held by employees which are mostly knowledge workers in the knowledge economy.

Explicit knowledge may be easily codified to tangible forms such as manuals, videos and other documents, thus owned by the organization. But the tacit knowledge is hard to be shared 
and transferred among employees. Since this tacit part of organizational knowledge amounts to a large proportion, knowledge management performance depends on the successful management of tacit knowledge, which involves more interaction between humans.

The performance of human interaction is influenced by many factors since the complexity of humans as social, economic and political creatures. An organization is a socioeconomic system, consisting of humans that are gathered for some common objectives along with their individual intensions. Organizational culture could be such an organizational factor that has an influence on knowledge management practices in organizations since it obviously impacts the way that employees interact with each other.

This paper attempts to explore the relationship between knowledge management and organizational culture in the specific situation of Chinese commercial banking industry. Section 2 reviews the related research in knowledge management and organizational culture. Section 3 explains the research methodology and data sample in this paper. Section 4 shows the analysis results and makes some discussion. Section 5 concludes with limitations and future work.

\section{Literature Review}

\subsection{Knowledge Management}

Knowledge management $(\mathrm{KM})$ has received extraordinary attention from academia and practitioners, especially recently with the development of knowledge-based economy. Knowledge has been considered as the important source of sustainable competitive advantage for organizations (Prahalad \& Hamel, 1990; Nonaka, 1991; Kogut \& Zander, 1992; Grant, 1996). Davenport and Prusak (2000) defined knowledge as "a fluid mix of framed experience, values, contextual information, and expert insights that provides a framework for evaluating and incorporating new experiences and information". From the knowledge-based view, a firm is considered as a set of knowledge assets and the role of the firm as creating and deploying these assets to create value (Grant, 1996; Pinho et al., 2012).

The firm plays the knowledge-creating role by enacting knowledge conversion process between tacit and explicit knowledge - Socialization, Externalization, Combination, and Internalization, briefly mentioned as SECI process (Nonaka, 1994; Nonaka \& Takeuchi, 1995; Nonaka et al., 2000; Magnier-Watanabe et al., 2011). Knowledge transfer of creative theories and practices is also important in the creative management in the $21^{\text {st }}$ century (Janáková, 2012; Xu \& Rickards, 2007).

KM has evolved from the computational paradigm to organic paradigm (Hazlett et al., 2005; Mueller, 2012). These two paradigms correspond with codification strategy and personalization strategy (Hansen et al., 1999). The former paradigm or strategy is more suitable to manage explicit knowledge, while the latter is fit for tacit knowledge that is held in the human mind and difficult to be codified.

$\mathrm{KM}$ encompasses the managerial efforts in facilitating activities of acquiring, creating, sharing, transferring and applying knowledge by individuals and groups (Rowley, 2001; Zheng et al., 2010). KM processes are influenced by individual, socio-organizational, and 
technological facilitators or barriers (Armistead, 1999; Rego et al.2009; Pinho et al., 2012). Knowledge-centered or knowledge-friendly culture is a critical factor for successful KM practices (Cardoso et al., 2012).

\subsection{Organizational Culture}

Organizational culture (OC) is defined as "the set of shared, taken-for-granted implicit assumptions that a group holds and that determines how it perceives, thinks about, and reacts to its various environments" (Schein, 1996). OC can become a source of sustainable competitive advantage if that culture is valuable, rare, and imperfectly imitable (Barney, 1986).

From the functionalist perspective of OC (Martin, 1992), OC works as the normative glue that allows for coordination and stability (Mueller, 2012). It can create value for an organization since it can simplify information processing, decrease the supervision cost and smooth the bargaining between employees (Besanko et al., 1996).

Denison and Mishra (1995) link OC with organizational effectiveness and explore the relationship between four culture traits and effective criteria such as profitability, quality, employee satisfaction and overall performance. OC has much more influences on organizational performance by impacting the psychological sate of individuals and ethical environment in the organization. Some psychological measures have been developed such as job satisfaction (Weiss et al., 1967; Lim, 2010; Bellou, 2010), organizational commitment (Meyer and Allen, 1991; Meyer et al., 2002; Meyer et al., 2012), and psychological empowerment (Spreitzer, 1995).

\subsection{Relationship between Knowledge Management and Organizational Culture}

Similar with the linkage between OC and effectiveness, there exists the relationship between KM and OC. Obviously OC influences the KM practices since KM encompasses human interaction. Knowledge-centered culture is defined by values and norms that nurture and explore organizational knowledge and continuous learning (Janz \& Prasarnphanich, 2003; Cardoso et al., 2012). Besides OC, other organizational characteristics also impact KM processes, such as organizational structure and leadership (Magnier-Watanabe et al., 2011).

KM can also work as a mediator between OC and organizational effectiveness, that is, OC can indirectly influence organizational effectiveness by its direct impact on KM (Zheng et al., 2010). Furthermore, Mueller (2012) discusses the interactive relationship between corporate culture and $\mathrm{KM}$, and on the contrary side, KM can also change OC.

\section{Research Methodology and Data Sample}

This research attempts to empirically explore the relationship between KM and OC. KM process is measured by a 24-item questionnaire, which is a five-point Likert scale. The six of 24 items respectively reflect one mode of Socialization, Externalization, Combination and Internalization (Nonaka, 1994; Nonaka \& Takeuchi, 1995; Nonaka et al., 2000).

The cyclic knowledge-creation process starts with socialization mode, where the tacit knowledge is acquired by dense interaction with customers, competitors or colleagues. The 
tacit knowledge is then externalized into explicit knowledge and can be shared within the firm. Then, the explicit knowledge is combined with other existing explicit knowledge to form a more complete and practical set of knowledge. Finally, organizational members internalize the newly created knowledge through application. In the next loop, the SECI process is continued and the organizational knowledge set is spirally increased. The balanced SECI modes are correlated with better financial performance (Riera et al., 2009) and the organization needs to enact KM practices for obtaining a balanced SECI process (Magnier-Watanabe et al., 2011).

OC is measured by employing Denison Organizational Culture Survey (DOCS). Four cultural traits - involvement, consistency, adaptability and mission - are found to be related to organizational effectiveness (Denison \& Mishra, 1995; Fey \& Denison, 2003). Briefly, involvement means empowerment, ownership and commitment; consistency means the degree of normative integration; adaptability means the capacity for internal change in response to external conditions; mission means a long-term vision (Denison \& Mishra, 1995). This research uses the 36-item scale of DOCS (Fey \& Denison, 2003), derived from the original version with 60 items.

Figure 1 illustrates the research model in this paper. The relationship between OC and KM process will be investigated. Furthermore, the detailed relationship between the four cultural traits and four SECI modes are studied, which has not been concerned by previous research as far as we know.

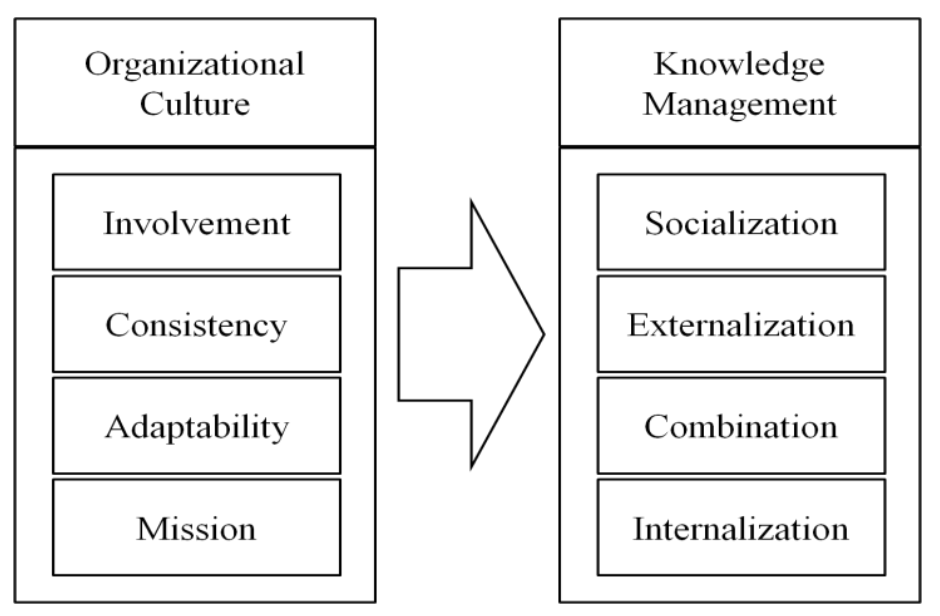

Figure 1 Research Model

This paper is just aiming to report the exploratory result in the initial stage of a project to study organizational effectiveness of banking industry in China. Thus the data sample is not so large at this stage. We investigate 18 banks in central China, and 33 respondents are all managerial staffs who have better understanding of the organization. So this paper can make some explanation about the empirical relationship between KM and OC. Furthermore, the approach used in this paper can be employed to enact an industry-wide survey in a large scale, which is actually what to do next in our future research agenda. 
Table 1 Reliability of DOCS

\begin{tabular}{llr}
\hline \multicolumn{1}{c}{ Cultural Dimension \& Cultural Traits } & Scale Item & Cronbach's Alpha \\
\hline CD1: Empowerment & $\mathrm{S} 1-3$ & 0.652 \\
CD2: Team orientation & $\mathrm{S} 4-6$ & 0.599 \\
CD3: Capability development & $\mathrm{S} 7-9$ & 0.595 \\
CD4: Team orientation & $\mathrm{S} 10-12$ & 0.651 \\
CD5: Agreement & $\mathrm{S} 13-15$ & 0.247 \\
CD6: Coordination and integration & $\mathrm{S} 16-18$ & 0.866 \\
CD7: Creating change & $\mathrm{S} 19-21$ & 0.391 \\
CD8: Customer focus & $\mathrm{S} 22-24$ & 0.550 \\
CD9: Organizational learning & $\mathrm{S} 25-27$ & 0.677 \\
CD10: Strategic direction and intent & $\mathrm{S} 28-30$ & 0.564 \\
CD11: Goals and objectives & $\mathrm{S} 31-33$ & 0.688 \\
CD12: Vision & $\mathrm{S} 31-36$ & 0.744 \\
\hline CT1: Involvement & $\mathrm{S} 1-9$ & 0.798 \\
CT2: Consistency & $\mathrm{S} 10-18$ & 0.655 \\
CT3: Adaptability & $\mathrm{S} 19-27$ & 0.381 \\
CT4: Mission & $\mathrm{S} 27-36$ & 0.846 \\
\hline Composite Reliability & $\mathrm{S} 1-36$ & 0.895 \\
\hline \hline
\end{tabular}

Table 2 Reliability of SECI Scale

\begin{tabular}{llr}
\hline \hline \multicolumn{1}{c}{ KM Modes } & Scale Item & Cronbach's Alpha \\
\hline KM1: Socialization & K1-6 & 0.596 \\
KM2: Externalization & K7-12 & 0.750 \\
KM3: Combination & K13-18 & 0.732 \\
KM4: Internalization & K19-24 & 0.603 \\
\hline Composite Reliability & K1-24 & 0.897 \\
\hline \hline
\end{tabular}

\section{Data Analysis and Discussion}

\subsection{Reliability and Descriptive Statistics}

Table 1 shows the reliability of DOCS scale in this data sample. Two of the 12 cultural dimensions and one of the 4 cultural traits show the unacceptable results because their Cronbach's Alpha coefficients are below 0.5. Since the other coefficients are well above 0.5 and the composite reliability is good (0.8-0.9), it is still meaningful to make some exploratory analysis.

Table 2 shows that the reliability of SECI scale is nearly above 0.6 and the composite reliability is also good. The average scores of the SECI modes (KM1-KM4), cultural traits (CT1-CT4), and cultural dimensions (CD1-CD12) are shown in Figure 2. From the SECI process, socialization and internationalization show the higher scores than the other two modes. This U-shape pattern of SECI process is consistent with previous research in KM (Magnier-Watanabe et al., 2011). The balance of SECI modes can only be obtained by KM initiatives. The unbalanced one provides space for the organization to enact KM practice in 
order to enable knowledge creating and sharing.

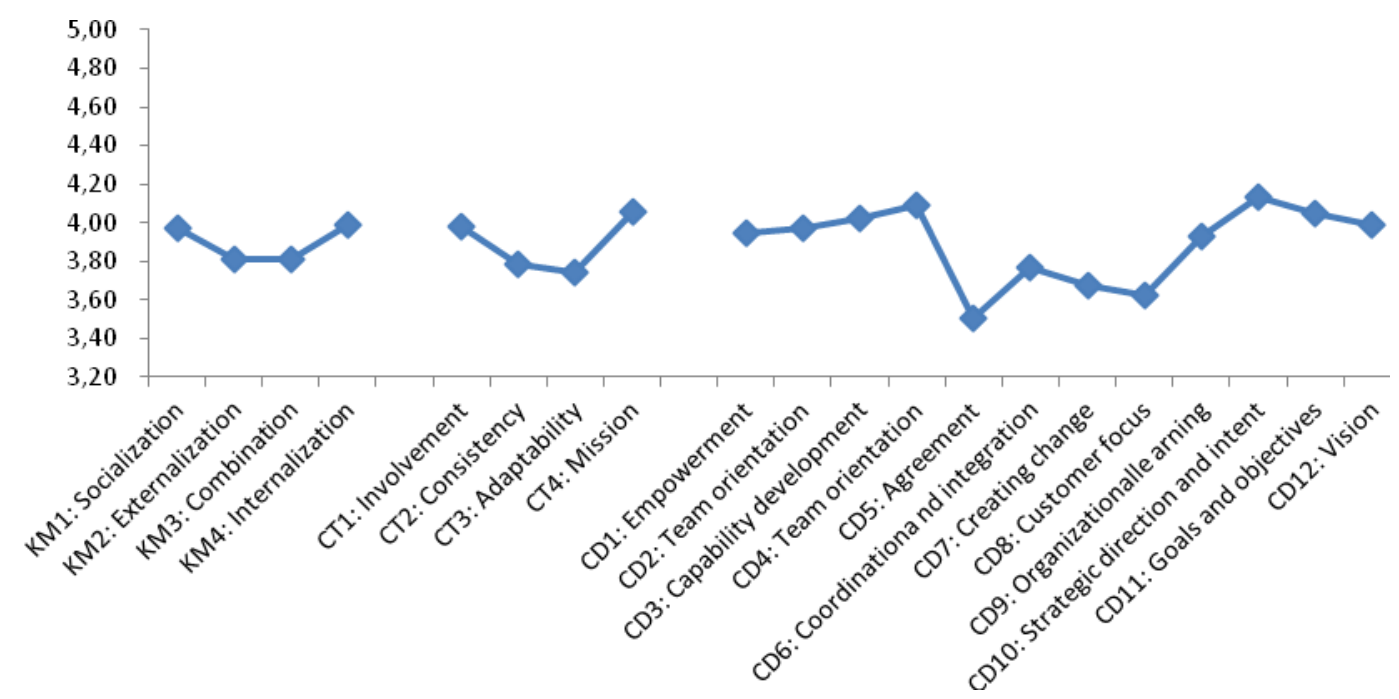

Figure 2 Descriptive Statistics of KM and DOCS items

In the four cultural traits, involvement and mission have higher scores than the cultural traits of consistency and adaptability. In detail, involvement (CT1) is measured by three cultural dimensions - empowerment (CD1), team orientation (CD2), capability development (CD3) - which have higher scores. Consistency and adaptability show lower scores, which is consistent with the lower scores of cultural dimensions such as agreement (CD5), coordination and integration (CD6), creating change (CD7), and customer focus (CD8).

4.2 Relationship between SECI Modes and Cultural Traits

Table 3 Correlation between Cultural Traits and SECI modes

\begin{tabular}{lllllllll}
\hline \hline & $\mathrm{CT} 1$ & $\mathrm{CT} 2$ & $\mathrm{CT} 3$ & $\mathrm{CT} 4$ & $\mathrm{KM} 1$ & $\mathrm{KM} 2$ & $\mathrm{KM} 3$ & $\mathrm{KM} 4$ \\
\hline CT1: Involvement & 1.00 & & & & & & & \\
CT2: Consistency & $0.65^{* * *}$ & 1.00 & & & & & & \\
CT3: Adaptability & $0.69^{* * * *}$ & $0.38^{* *}$ & 1.00 & & & & & \\
CT4: Mission & $0.72^{* * *}$ & $0.64^{* * *}$ & $0.48^{* * *}$ & 1.00 & & & & \\
KM1: Socialization & $0.42^{* *}$ & $0.42^{* *}$ & $0.41^{* *}$ & $0.31^{*}$ & 1.00 & & & \\
KM2: Externalization & $0.43^{* *}$ & 0.26 & $0.46^{* * *}$ & $0.34^{*}$ & $0.69^{* * *}$ & 1.00 & & \\
KM3: Combination & $0.51^{* * *}$ & $0.48^{* * *}$ & $0.43^{* *}$ & $0.46^{* * *}$ & $0.80^{* * *}$ & $0.69^{* * *}$ & 1.00 & \\
KM4: Internalization & $0.57^{* * *}$ & $0.40^{* *}$ & $0.41^{* *}$ & $0.65^{* * *}$ & $0.62^{* * *}$ & $0.69^{* * *}$ & $0.69^{* * *}$ & 1.00 \\
\hline
\end{tabular}

*** $\mathrm{p}<0.01, * * \mathrm{p}<0.05, * \mathrm{p}<0.10$.

Table 3 gives the correlations between culture traits and SECI modes. Out of 28 correlations, 17 correlations are significant at the level of $0.01,8$ are significant at the level of 0.05 , and 2 are significant at the 0.10 level. Only the correlation between CT2 and KM2 is not significant. All the correlations are positive, showing the positive relationship between cultural traits and SECI modes. 
Table 4 shows the multiple regression result. SECI modes are dependent variables, and four cultural traits are independent variables. The coefficients of four cultural traits are not significant when they are all entered in the multiple regression equation for SECI modes. Thus the stepwise method is used and for each SECI mode, only one cultural trait is left in the final regression model.

As shown in Table 4, the cultural trait of involvement can explain $17.7 \%$ of the socialization and $26.2 \%$ of the combination. Involvement positively impacts the socialization (0.420) and combination (0.512). Adaptability explains $21.2 \%$ of the externalization and has a positive influence on the externalization (0.460). Mission explains $42.8 \%$ of the internalization and impacts it greatly (0.655). The regression models are nearly all significant at the level of 0.01 .

Table 4 Analysis Result of Stepwise Multiple Regression

\begin{tabular}{|c|c|c|c|c|}
\hline & KM1: Socialization & KM2: Externalization & KM3: Combination & KM4: Internalization \\
\hline CT1: Involvement & 0.420 & & 0.512 & \\
\hline R Square & 0.177 & & 0.262 & \\
\hline F & 6.645 & & 11.023 & \\
\hline Sig. & 0.015 & & 0.002 & \\
\hline \multicolumn{5}{|l|}{ CT2: Consistency } \\
\hline \multicolumn{5}{|l|}{ R Square } \\
\hline \multicolumn{5}{|l|}{ F } \\
\hline \multicolumn{5}{|l|}{ Sig. } \\
\hline CT3: Adaptability & & 0.460 & & \\
\hline R Square & & 0.212 & & \\
\hline F & & 8.337 & & \\
\hline Sig. & & 0.007 & & \\
\hline CT4: Mission & & & & 0.655 \\
\hline R Square & & & & 0.428 \\
\hline $\mathrm{F}$ & & & & 23.241 \\
\hline Sig. & & & & 0.000 \\
\hline
\end{tabular}

4.3 Total effect of Organizational Culture on Knowledge Management

To measure the total effect that OC has on KM, the partial least squares (PLS) analysis is used (Gefen et al., 2000; Tseng \& Fan, 2011). Table 5 provides the PLS analysis result. The reliability is accepted since the Cronbach's Alpha coefficients exceed 0.80. The R square is 0.365 , meaning that OC can explain $36.5 \%$ of KM (SECI process).

Table 5 Quality Criteria of PLS Analysis

\begin{tabular}{ccccc}
\hline \hline & AVE & Composite Reliability & R Square & Cronbachs Alpha \\
\hline KM & 0.770 & 0.931 & 0.365 & 0.901 \\
OC & 0.700 & 0.903 & & 0.855 \\
\hline
\end{tabular}




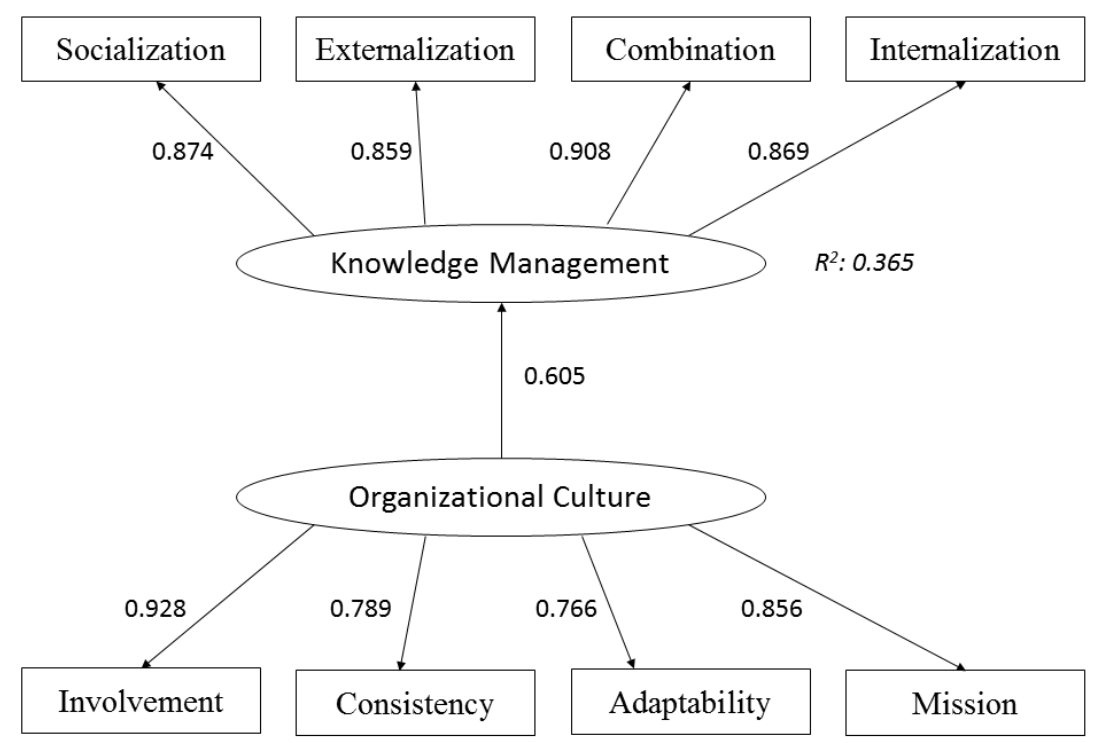

Figure 3 Path Coefficients of PLS Analysis

In detail, Figure 3 provides path coefficients for the PLS analysis. OC and KM are two latent variables in this model, which are reflectively measured by the four cultural traits and four SECI modes. The path coefficient from OC to KM is 0.605 , which totally reflects the great positive effect that $\mathrm{OC}$ has on $\mathrm{KM}$.

\section{Conclusions}

This paper is attempting to report some exploratory results at the initial stage of an industry-wide survey. Although the analysis results are constrained by its sampling size, some meaningful outcomes can be obtained, deserving future research to provide more evidence.

Firstly, the U-shape pattern of SECI modes shows the needs to initiate KM practices in the banking industry. These four modes make up of a cyclic knowledge process and more balanced SECI modes induce better organizational performance. The organization needs to enact KM practices to obtain a balanced SECI process.

Secondly, OC impacts KM. From the perspective of total effect, OC as a whole has a greatly positive influence on KM. This shows us the important role of OC in KM. KM practices should be accompanied by cultural intervention. Furthermore, for the respective mode of SECI process, four cultural traits have different effects on four SECI modes. This relationship shows some possible way to improve one SECI mode by promoting one cultural trait.

Moreover, this paper provides the empirical approach to analyze $\mathrm{KM}$ and its facilitating factors by employing the statistical analysis of correlation, regression and structural equation modeling. Future survey data can be analyzed in similar way. The scales of Denison Organizational Culture survey and SECI modes are proper instruments to be used to explore the relationship between $\mathrm{OC}$ and $\mathrm{KM}$. 
Some limitations exist in this paper and future research work can be done. Based on the exploratory study by far, an industry-wide survey can be conducted subsequently and more evidence can be found to testify the present results. Besides, more factors needs to be considered such as organizational commitment which reflects the individual psychological state. Lastly, a longitudinal research will help to understand the evolution and interaction between OC and KM. That is why we plans to build a web system to enact industry-wide and periodical surveys.

\section{Acknowledgement}

This work was supported in part by the Humanities and Social Science Fund of Shanxi University (No.1009011). The authors gratefully thank Dr. Magnier-Watanabe for his provision of the SECI scale, based on which we made the survey instrument for knowledge management in this paper. We also thank Haiyan Gao, and Xin Zhao for their work in implementing the survey and collecting the data.

\section{References}

Armistead, C. (1999). Knowledge management and process performance. Journal of Knowledge Management, 3(2), 143-157.

Barney, J. B. (1986). Organizational Culture: Can It Be a Source of Sustained Competitive Advantage? The Academy of Management Review, Vol. 11, No. 3, pp. 656-665, Jul., 1986.

Bellou, V. (2010). Organizational culture as a predictor of job satisfaction: the role of gender and age. Career Development International, Vol. 15, No.1, pp. 4 - 19.

Besanko, D., Dranove, D., Shanley, M. (1996). The Economics of Strategy. John Wiley.

Cardoso, L., Meireles, A., \& Peralta, C. F. (2012). Knowledge management and its critical factors in social economy organizations. Journal of Knowledge Management, 16(2), 267-284.

Davenport, T. H., \& Prusak, L. (2000). Working knowledge: How organizations manage what they know. Harvard Business Press.

Davenport, T. H., De Long, D. W., \& Beers, M. C. (1998). Successful knowledge management projects. Sloan management review, 39(2), 43-57.

Denison, D. R., Mishra, A. K. (1995). Toward a Theory of Organizational Culture and Effectiveness. Organization Science, Vol. 6, No. 2, pp. 204-223.

Drucker, P. F. (1999). Knowledge-worker productivity. California management review, 41(2), 
$79-94$

Fey, C. F, Denison, D. R. (2003). Organizational Culture and Effectiveness: Can American Theory Be Applied in Russia? Organization Science, Vol. 14, No. 6, pp. 686-706.

Gefen, D., Straub, D. W., \& Boudreau, M. C. (2000). Structural equation modeling and regression: Guidelines for research practice. Communications of the Association for Information Systems 4(7), 1-76.

Grant, R. M. (1996). Toward a knowledge-based theory of the firm. Strategic management journal, 17, 109-122.

Hansen, M., T., Nohria, N., \& Tierney, T. (1999). What's your strategy for managing knowledge? Harvard Bussiness Review, 106-116 (March).

Hazlett, S. A., McAdam, R., \& Gallagher, S. (2005). Theory building in knowledge management in search of paradigms. Journal of Management Inquiry, 14(1), 31-42.

Janáková, H. (2012). Creative Management and Innovation. Creative and Knowledge Society, Vol. 2, No. 1, 95-112.

Janz, B. D., \& Prasarnphanich, P. (2003). Understanding the Antecedents of Effective Knowledge Management: The Importance of a Knowledge-Centered Culture. Decision sciences, 34(2), 351-384.

Kogut, B., \& Zander, U. (1992). Knowledge of the firm, combinative capabilities, and the replication of technology. Organization science, 3(3), 383-397.

Lim, T. (2010). Relationships among organizational commitment, job satisfaction, and learning organization culture in one Korean private organization. Asia Pacific Education Review (2010) 11:311-320.

Magnier-Watanabe, R., Benton, C., \& Senoo, D. (2011). A study of knowledge management enablers across countries. Knowledge management research \& practice, 9(1), 17-28.

Martin, J. (1992). Cultures in organizations: three perspectives. Oxford University Press, New York

Martin, J. (1992). Cultures in organizations: three perspectives. Oxford University Press, New York

Meyer, J. P., \& Allen, N. J. (1991). A three-component conceptualization of organizational 
commitment. Human Resource Management Review, 1, 61-89.

Meyer, J. P., Stanley, D. J., Herscovitch, L., \& Topolnytsky, L. (2002). Affective, continuance and normative commitment to the organization: A meta-analysis of antecedents, correlates and consequences. Journal of Vocational Behavior, 61, 20-52.

Meyer, J. P., Stanley, L. J., \& Parfyonova, N. M. (2012). Employee commitment in context: The nature and implications of commitment profiles. Journal of Vocational Behavior, 80 , $1-16$.

Mueller, J. (2012). The interactive relationship of corporate culture and knowledge management: a review. Review of Managerial Science, 6(2), 183-201.

Nonaka, I., \& Takeuchi, H. (1995). The Knowledge-creating Company: How Japanese Companies Create the Dynamics of Innovation. Oxford University Press, New York.

Nonaka, I., Toyama, R., \& Konno, N. (2000). SECI, Ba and Leadership: a Unified Model of Dynamic Knowledge Creation. Long range planning, 33(1), 5-34.

Nonaka, I. (1991). The knowledge-creating company. Harvard Bussiness Review, 96-104 (Nov-Dec).

Nonaka, I. (1994). A dynamic theory of organizational knowledge creation. Organization Science 5(1), 14-37.

Pinho, I., Rego, A., \& e Cunha, M. P. (2012). Improving knowledge management processes: a hybrid positive approach. Journal of Knowledge Management, 16(2), 215-242.

Polanyi, M. (1983). The tacit dimension (pp. 21-25). Gloucester, MA: Peter Smith.

Prahalad,C. K., \& Hamel, G. (1990). The core competence of the corporation. Harvard business review, 68, 79-93.

Rego, A., Pinho, I., Pedrosa, J. \& Cunha, M. P. (2009). Barriers and facilitators to knowledge management in university research centers: an exploratory study. Management Research, 7(1), 33-47.

Riera, C. G., Senoo, D., \& Iijima, J. (2009). A study of the effect of knowledge creating capabilities on corporate performance. International Journal of Knowledge Management Studies, 3(1), 116-133.

Rowley, J. (2001). Knowledge management in pursuit of learning: the learning with 
knowledge cycle. Journal of Information Science, 27(4), 227-237.

Schein, E. H. (1996). Culture: The Missing Concept in Organization Studies. Administrative Science Quarterly, Vol. 41, No. 2, 40th Anniversary Issue, pp. 229-240.

Spreitzer, G. M. (1995). Psychological empowerment in the workplace: Dimensions, measurement, and validation. Academy of Management Journal, 38(5), 1442-1465.

Tseng, F. C., \& Fan, Y. J. (2011). Exploring the influence of organizational ethical climate on knowledge management. Journal of business ethics, 101(2), 325-342.

Weiss, D. J., Dawis, R. V., England, G. W., \& Lofquist, L. H. (1967). Manual for the Minnesota Satisfaction Questionnaire. Minneapolis, MN: Work Adjustment Project of the University of Minnesota.

Xu, F., \& Rickards, T. (2007). Creative management: A predicted development from research into creativity and management. Creativity and Innovation Management, 16(3), 216-228.

Zheng, W., Yang, B., \& McLean, G. N. (2010). Linking organizational culture, structure, strategy, and organizational effectiveness: Mediating role of knowledge management. Journal of Business Research, 63(7), 763-771.

\section{About the Authors}

\section{Bing Li}

$\mathrm{He}$ is now a postdoctoral researcher in Financial Research Center of Fudan University (China). He also works as a lecturer in the School of Economics and Business Administration, Shanxi University (China). His doctor degree was from the Department of industrial Engineering and Management in Tokyo Institute of Technology (Japan), his master degree and bachelor degree was from Xi'an Jiaotong University (China). His research interests include information systems, organizational culture, and finance. He can be contacted at libingfd@fudan.edu.cn

\section{Jianpeng Zhang}

He is a postdoctoral researcher in Financial Research Center of Fudan University (China). His doctor degree was from Tomas Bata University (CZ). His research is concentrated on insurance economics, finance regulation and creative economy. He can be contacted at zlintbu@163.com.

\section{Xiaoxia Zhang}

She is a PhD candidate in the Graduate School of Economics in Rikkyo University (Japan). She is also a lecturer in the School of Foreign Languages, Shanxi University (China). Her 
master degree in Arts was from Shanxi University and master degree in Economics was from Rikkyo University. Her present research includes organizational culture, cross culture management and culture intelligence. 